\title{
Genetic correlation between plasma levels of C4BP isoforms containing $\beta$ chains and susceptibility to thrombosis
}

\author{
J Esparza-Gordillo, J M Soria, A Buil, J C Souto, L Almasy, J Blangero, S R de Córdoba, \\ J Fontcuberta
}

J Med Genet 2004;41:e5 (http://www.jmedgenet.com/cgi/content/full/41/1/e5)

$\mathrm{T}$ hrombosis is a complex trait with both genetic and environmental components. ${ }^{1}$ In general, disease status is a qualitative trait where individuals are diagnosed as affected or unaffected, but it is now accepted that underlying the disease there is a continuum trait termed liability, susceptibility, or risk. Liability cannot be measured directly, but it can be modelled and estimated. Disease results when an individual's liability is above a critical value or threshold, whereas liability values below the threshold correspond to healthy individuals. These threshold models of an underlying continuous scale of risk allow inferences that are compatible with current models of gene action. ${ }^{2}$

Quantitative plasma phenotypes, such as those related to haemostasis, are also complex traits, whose regulation depends on multiple genetic and environmental factors. ${ }^{3}$ Classical statistical methods are unable to quantify or partition the genetic and environmental factors determining the variability in such complex traits. However, variance component methods have been developed which allow the examination of sources of correlation between quantitative physiological measures and disease outcomes. ${ }^{4}$ These statistical genetic methods also permit the localisation and evaluation of the relative effects of the genes involved. ${ }^{5}$

We have applied these methods to the Genetic Analysis of Idiopathic Thrombophilia Project (GAIT Project) to characterise the genetic determinants responsible for idiopathic thrombophilia. Using a family based approach, we estimated that idiopathic thrombophilia has a heritability of 0.61 , indicating that $61 \%$ of variation in liability to thrombosis at the population level can be attributed to genetic factors. ${ }^{6}$ Phenotypic correlations were also evaluated between 27 plasma phenotypes related to haemostasis and thrombosis liability. ${ }^{6}$ It was found that genetic factors were mainly responsible for these phenotypic correlations, ${ }^{6}$ indicating that some of the genes that regulate quantitative variation in these plasma phenotypes also affect the risk of thrombosis. These pleiotropic effects have been successfully exploited to improve the power to detect the QTL contributing to thrombotic risk. ${ }^{7-9}$

C4BP is a plasma protein composed of two polypeptides ( $\alpha$ and $\beta$ chains) which form three plasma oligomers $\left(\alpha_{7} \beta_{1}, \alpha_{7} \beta_{0}\right.$ and $\alpha_{6} \beta_{1}$ ) with different subunit compositions. ${ }^{10}$ The C4BP $\beta^{+}$ isoforms bind free protein S (PS) with high affinity, blocking the PS anticoagulatory cofactor activity of the activated protein C (APC) pathway. ${ }^{10-12}$ Thus, free PS, but not C4BP $\beta^{+}$ bound PS, is functional as an APC cofactor. Since free PS deficiency is a risk factor for thrombosis, it has been suggested that increased levels of $\mathrm{C} 4 \mathrm{BP} \beta^{+}$isoforms might affect the susceptibility to thrombosis by decreasing the plasma levels of free PS. ${ }^{11-14}$ We have reported previously that the variation in the $\mathrm{C} 4 \mathrm{BP} \beta^{+}$isoforms ${ }^{15}$ and the free $\mathrm{PS}^{16}$ plasma levels are genetically regulated, with heritabilities of $42 \%$ and $46 \%$, respectively. Moreover, the free PS plasma levels show genetic linkage (lod score $=4.07$; nominal

\section{Key points}

- We designed a family based study using a variance component method that allows the examination of sources of correlation between continuous physiological measures and discrete disease outcomes. The method also allows for the quantification of the genetic and environmental factors underlying the phenotypic correlation between traits.

- We applied these methods to the Genetic Analysis of Idiopathic Thrombophilia Project (GAIT) to characterise the genetic determinants responsible for idiopathic thrombophilia.

- The $\mathrm{C} 4 \mathrm{BP} \beta^{+}$isoforms exhibited significant phenotypic $\left(\rho_{p}=0.27 ; p=0.03\right)$ and genetic $\left(\rho_{g}=1 ; p<<0.0001\right)$ correlations with thrombosis. Interestingly, free and functional protein S (PS) showed no correlation with the disease.

- Our data demonstrate the existence of a phenotypic correlation between $\mathrm{C} 4 \mathrm{BP} \beta^{+}$and thrombosis that is most probably due to common genetic factors regulating both traits rather than a consequence of an effect of $\mathrm{C} 4 \mathrm{BP} \beta^{+}$on the free and functional PS plasma levels.

- The $C 4 B P \beta^{+}$trait is a new thrombosis related phenotype that should help to identify the quantitative trait locus (QTL) influencing the genetic liability to thrombotic disease.

$\mathrm{p}<<0.0001$ ) with the chromosome region 1q32, which contains the genes encoding the $\alpha$ and $\beta$ chains of C4BP. ${ }^{17}$

In this study we have applied the variance component method to assess the phenotypic, genetic and environmental correlations between total C4BP, C4BP $\beta^{+}$isoforms, total PS, free PS, functional PS plasma levels, and the thrombotic liability. The analyses revealed that plasma levels of $\mathrm{C} 4 \mathrm{BP} \beta^{+}$ isoforms show a phenotypic correlation with thrombosis, and that this correlation is due to a pleiotropic regulation on both traits rather than an effect of $\mathrm{C} 4 \mathrm{BP} \beta^{+}$on the plasma levels of free PS.

\section{METHODS}

\section{Sample and phenotypes}

The GAIT Project is composed of 21 extended families, 12 of which were ascertained through a proband with idiopathic

Abbreviations: APC, activated protein C; GAIT Project, Genetic Analysis of Idiopathic Thrombophilia Project; PS, protein S; QTL, quantitative trait locus 
thrombophilia and nine of which were obtained randomly. Due to the lack of plasma samples in one of our thrombophilic pedigrees we only analysed 20 GAIT families, consisting of 358 individuals. Thrombophilia was defined as multiple thrombotic events, a single spontaneous episode with a first degree relative also affected, or onset of thrombosis younger than 45 years. Diagnoses of the thrombophilic probands were verified objectively. Thrombosis in an individual was considered idiopathic because of the exclusion of all biological causes of thrombosis at the time of recruitment (1995-97), including antithrombin deficiency, PS and PC deficiencies, activated PC resistance, plasminogen deficiency, heparin cofactor II deficiency, Factor V Leyden, dysfibrinogenaemia, lupus anticoagulant, and antiphospholipid antibodies. In this sample, 45 individuals had venous or arterial thrombosis, 39 of them in the families ascertained through a thrombophilic proband and six of them in the randomly ascertained families. There were more affected women $(n=24,53.3 \%)$ than men $(n=21,46.7 \%)$ and the age at diagnosis of first thrombosis ranged from 12 to 76 years, with a mean of 44.8 years. Deep vein thrombosis was the most common condition $(\mathrm{n}=23)$ and superficial thrombophlebitis was the second most common $(\mathrm{n}=10)$ (table 1).

The recruitment, sampling, collection of medical history and lifestyle, and phenotyping methods used in the GAIT Project have been extensively described in previous publications. ${ }^{6}{ }^{16}$ Total and free PS were measured with ELISA kits from Diagnostica Stago (Asnieres-Sur-Seine; France). Functional PS (APC cofactor activity) was assayed in an STA automated coagulometer (Boehringer Mannheim) with a kit from Diagnostica Stago. Total C4BP and C4BP $\beta^{+}$ isoforms plasma levels were measured with a home made ELISA method, as previously described. ${ }^{18}$

All procedures were approved by the Institutional Review Board of the Hospital de la Santa Creu i Sant Pau. Adult subjects gave informed consent for themselves and for their children.

\section{Statistical analysis}

The susceptibility to thrombosis was modelled as a threshold process using a pedigree based maximum likelihood method. ${ }^{19}$ The threshold is placed in an age and sex specific manner to produce the appropriate population prevalence. To use a threshold model, some weak assumptions regarding the form of the underlying continuous process are necessary. For genetic modelling, we assumed that the underlying liability distribution was normal, and we calculated the joint probability of observing the disease statuses of family members by using a multivariate normal distribution that allowed for correlations among family members.

To study the relationships between thrombosis liability and quantitative variation in the plasma parameters, we used a mixed discrete/continuous trait variance component analysis. ${ }^{4}$ This analysis allowed the decomposition of phenotypic correlations into factors caused by common genetic influences (pleiotropy) and common environmental influences on the two traits. All statistical genetic analyses were performed using the computer package SOLAR. ${ }^{5}$ All hypotheses were tested using likelihood ratio test statistics. ${ }^{20}{ }^{21}$ Age, sex, smoking habits, and the use of oral contraceptives were used as covariates in the analyses, based on our previous reports. $^{1517}$

Because 11 of the 20 pedigrees were ascertained through a thrombophilic proband, an ascertainment correction was included to allow an unbiased estimation of parameters relevant to the general population. To achieve this, the likelihood for each family ascertained through a thrombophilic proband was conditioned on the phenotype of the proband. ${ }^{22} 23$

\section{RESULTS}

This is the first study that evaluated the phenotypic, genetic, and environmental correlations between thrombosis susceptibility and total C4BP, C4BP $\beta^{+}$isoforms, total PS, free PS and functional PS plasma levels. The results are summarised in table 2. The $\mathrm{C} 4 \mathrm{BP} \beta^{+}$plasma levels and the thrombosis liability showed a positive phenotypic correlation $\left(\rho_{p}=0.27\right.$; $\mathrm{p}=0.03$ ), indicating that the $\mathrm{C} 4 \mathrm{BP} \beta^{+}$plasma levels tend to be increased in affected individuals. More importantly, the genetic correlation between $\mathrm{C} 4 \mathrm{BP} \beta^{+}$and thrombosis was very high $\left(\rho_{g}=1 ; p<0.0001\right)\left(\rho_{g}\right.$ between 0.55 and 1 for the $95 \%$ confidence interval). C4BP $\beta^{+}$and thrombosis showed a marginally significant negative environmental correlation $\left(\rho_{\mathrm{e}}=-0.27 ; \mathrm{p}=0.09\right)$, which suggests that there are common environmental factors exerting opposite effects in the $\mathrm{C} 4 \mathrm{BP} \beta^{+}$levels and the thrombotic susceptibility. Total C4BP plasma level showed no statistically significant phenotypic correlation with thrombosis susceptibility, but it was genetically correlated with the disease $\left(\rho_{\mathrm{g}}=0.54\right.$; $\mathrm{p}=0.02$ ).

Another important observation is that total, free and functional PS plasma levels lack phenotypic, genetic and environmental correlation with thrombosis (table 2). These data suggest that variation in the free PS plasma levels and in the PS APC cofactor activity (functional PS) are unrelated to thrombotic susceptibility in our sample.

Table 1 Number and percent of individuals in each diagnostic category of thrombosis and age at diagnosis

\begin{tabular}{lcl}
\hline Diagnosis & $\mathrm{N}$ (\% of individuals) & $\begin{array}{l}\text { Mean age at diagnosis } \\
\text { (years) }\end{array}$ \\
\hline $\begin{array}{l}\text { Venous thrombosis } \\
\text { Deep vein thrombosis }\end{array}$ & $23(51.1)$ & 41.0 \\
Pulmonary embolism & $8(17.8)$ & 46.6 \\
Superficial thrombophlebitis & $10(22.2)$ & 38.8 \\
Other venous thrombosis & $3(6.7)$ & 58.0 \\
Any venous thrombosis & $33(73.3)$ & 40.5 \\
Arterial thrombosis & $3(6.7)$ & 65.3 \\
Myocardial infarction & $4(8.9)$ & 57.3 \\
Angina pectoris & $6(13.3)$ & 61.0 \\
Ischaemic stroke & $4(8.9)$ & 52.3 \\
Transient ischaemic attack & $15(33.3)$ & 59.9 \\
Any arterial thrombosis & $45(100)$ & 44.8 \\
Any thrombosis & \\
\hline Note: some individuals are included in more than one diagnostic category. & \\
\hline
\end{tabular}


Table 2 Phenotypic, genetic and environmental correlations between quantitative plasma phenotype and thrombotic liability

\begin{tabular}{|c|c|c|c|}
\hline Phenotype & $\rho_{p}$ (p value) & $\rho_{g}$ ( $p$ value) & $\rho_{e}$ (p value) \\
\hline Total C4BP & $0.18(0.07)$ & $0.54(0.02)$ & $-0.13(\mathrm{~ns})$ \\
\hline $\mathrm{C} \mathrm{BPP} \beta^{+}$ & $0.27(0.03)$ & $1.00(<<0.0001)^{\dagger}$ & $-0.27(0.09)$ \\
\hline Total PS & 0.12 (ns) & 0.26 (ns) & -0.02 (ns) \\
\hline Free PS & 0.07 (ns) & $0.35(0.07)$ & $-0.29(\mathrm{~ns})$ \\
\hline Functional PS & $-0.18(\mathrm{~ns})$ & -0.09 (ns) & $-0.30(\mathrm{~ns})$ \\
\hline APCR $\ddagger$ & $-0.23(0.0003)$ & $-0.65(<<0.0001)$ & $0.66(<<0.0001)$ \\
\hline FVIII & $0.28(0.0002)$ & $0.68(0.0005)$ & -0.12 (ns) \\
\hline t-PAf & $0.18(0.0002)$ & $0.75(0.007)$ & $-0.10(\mathrm{~ns})$ \\
\hline vWF & $0.26(0.0001)$ & $0.72(0.0005)$ & $-0.18(\mathrm{~ns})$ \\
\hline R1s & $-0.31(0.0006)$ & $-1.00(<<0.0001)$ & $0.38(0.06)$ \\
\hline
\end{tabular}

$P$ values for $\rho \neq 0$ are shown in parenthesis; ns, non-significant $(p>0.1) ; \rho_{p}$, phenotypic correlation; $\rho_{g}$, genetic correlation; $\rho_{e}$, environmental correlation; $\dagger$ The $95 \%$ confidence interval of the genetic correlation between $\mathrm{C} 4 \mathrm{BP} \beta^{+}$and thrombosis is $(0.55-1)$. $\neq$ Data extracted from Souto ef al ${ }^{6}$ showing the four phenotypes with the highest phenotypic and genetic correlations with thrombosis from a panel of 40 haemostasis related phenotypes. \$Thromboplastin thrombomodulin mediated time ${ }^{20}$. APCR, Activated Protein C Resistance; FVIII, Factor VIII; t-PA, tissue plasminogen activator; vWF, von Willebrand Factor.

As a whole, these data indicate that there are common genetic factors (pleiotropy) underlying variation of both $\mathrm{C} 4 \mathrm{BP} \beta^{+}$plasma levels and thrombotic liability.

\section{DISCUSSION}

In this study, we have used a variance component method to decompose the phenotypic correlations between thrombosis liability and the C4BP and PS plasma phenotypes into genetic and environmental components. The positive phenotypic correlation $\left(\rho_{\mathrm{p}}=0.27\right.$ ) between $\mathrm{C} 4 \mathrm{BP} \beta^{+}$plasma level and the thrombotic liability that we found indicates that affected individuals tend to have increased levels of $\mathrm{C} 4 \mathrm{BP} \beta^{+}$, but this does not necessarily imply a causal relationship between both traits. The genetic correlation between $\mathrm{C} 4 \mathrm{BP} \beta^{+}$and thrombosis is extremely high $\left(\rho_{\mathrm{g}}=1 ; 95 \%\right.$ confident interval $0.55-$ 1). Notably, this is the highest genetic correlation that we have obtained after testing for pleiotropy among thrombotic liability and 40 quantitative haemostasis phenotypes, ${ }^{6}{ }^{24}$ some of which are widely accepted thrombotic risk factors ${ }^{25-27}$ (table 2 includes some of these previously published results for comparison). Thus, the data presented here provide strong evidence that the $\mathrm{C} 4 \mathrm{BP} \beta^{+}$trait is a thrombotic related phenotype.

$\mathrm{C} 4 \mathrm{BP} \beta^{+}$and thrombosis show a negative environmental correlation $\left(\rho_{\mathrm{e}}=-0.27\right)$. The correlation between $\mathrm{C} 4 \mathrm{BP} \beta^{+}$ and thrombosis is a good example of how low phenotypic correlations may misrepresent the true underlying relationships. In this case, the strong positive genetic correlation is attenuated by a low negative environmental correlation, leading to a moderate phenotypic correlation (table 2). Other investigators have reported similar results using bivariate genetic analysis of a variety of traits. ${ }^{28-30}$

As expected, total PS plasma levels showed no correlation with the disease. Interestingly, free and functional PS plasma levels also lacked phenotypic, genetic or environmental correlations with thrombosis. These data indicate that the contribution of free and functional PS to thrombosis is probably limited to the PS deficiencies. The risk of thrombosis associated with PS deficiency is a controversial issue. ${ }^{31-34}$ In this respect, it should be remembered that because the GAIT Project attempted to identify genetic factors underlying idiopathic thrombophilia, PS deficient families were excluded from the sample. ${ }^{616}$ This explains the lack of correlations among the PS plasma phenotypes and the thrombotic liability in the present study. Our data fit with previous reports $^{153536}$ showing that there is a weak phenotypic correlation between C4BP $\beta^{+}$and free PS $\left(\rho_{\mathrm{p}}=0.25\right.$; $\mathrm{p}<0.001)$, ${ }^{15}$ since increases in $\mathrm{C} 4 \mathrm{BP} \beta^{+}$seem to be compensated for by elevated total PS plasma levels $\left(\rho_{p}=0.57\right.$; $\left.\mathrm{p}<0.001 . \rho_{\mathrm{g}}=0.49 ; \mathrm{p}<0.01\right) .{ }^{15}$ Taken together, the genetic correlation between $\mathrm{C} 4 \mathrm{BP} \beta^{+}$and thrombosis points to a pleiotropic regulation of $\mathrm{C} \mathrm{BP}^{+}$plasma levels and susceptibility of thrombosis. If there is a causal relationship between C4BP $\beta^{+}$levels and thrombotic liability, it seems to be independent of $\mathrm{C} 4 \mathrm{BP} \beta^{+}$induced variation in the free and functional PS plasma levels.

In conclusion, the present work shows that the C4BP $\beta^{+}$ plasma level and the thrombotic liability are phenotypically correlated traits, and that genetic factors are mainly responsible for this correlation. Thus, the $\mathrm{C} 4 \mathrm{BP} \beta^{+}$plasma level must be considered a new thrombosis related phenotype. Thrombosis is a complex disease with both genetic and environmental components. ${ }^{1}$ Different studies have identified various haemostatic phenotypes ${ }^{21-23}$ as thrombotic risk factors. In addition, some of these quantitative risk factors exhibited significant genetic correlations with thrombosis, ${ }^{6}$ which has been exploited to improve the power to detect the quantitative trait locus (QTL) contributing to thrombotic risk. ${ }^{7-9}$ The $\mathrm{C} 4 \mathrm{BP} \beta^{+}$phenotype shows a sizeable genetic component (heritability $=42 \%)^{15}$ and a pleiotropic regulation with thrombosis (this work), indicating that it might be an intermediate thrombotic risk factor. Intermediate risk factors tend to be proximal to gene action and, when analysed, provide less attenuated genetic signals than discrete clinical endpoints, such as disease. The pleiotropy observed for $\mathrm{C}_{4} \mathrm{BP}^{+}$ and thrombosis should improve the power to identify QTLS contributing to thrombotic risk.

\section{ACKNOWLEDGEMENTS}

We would like to acknowledge the advice and helpful discussion of Professor W H Stone. We are deeply grateful to the families that participated in this study.

\section{Authors' affiliations}

J Esparza-Gordillo, S R de Córdoba, Departamento de Inmunología, Centro de Investigaciones Biológicas, Consejo Superior de Investigaciones Científicas, Madrid, Spain

J M Soria, A Buil, J C Souto, J Fontcuberta, Unitat d'Hemostàsia i Trombosi, Hospital de la Santa Creu i Sant Pau, Barcelona, Spain L Almasy, J Blangero, Southwest Foundation for Biomedical Research, San Antonio, TX, USA

This study was supported by grants NIH USA HL70751, FIS 02/0375 from the Fondo Investigación Sanitaria, SAF2002/03449 and SAF2002/01083 from the Spanish Ministry of Science and Technology, 08.6/0028.1/2000 from the Comunidad de Madrid, Fundació "La Caixa", and Fundació de Investgació Sant Pau. Dr J M Soria is supported by the FIS 99/3048 grant from the Fondo de Investigación Sanitaria. J Esparza-Gordillo is supported by a grant from the Comunidad Autónoma de Madrid. A Buil is supported by the FIS 01 / A046 grant from the Fondo Investigación Sanitaria. 
Correspondence to: Dr J M Soria, Unitat d'Hemostàsia i Trombosi, Hospital de la Santa Creu i Sant Pau, C/Sant Antoni M Claret, 167, 08025-Barcelona, Spain; jsoria@hsp.santpau.es

Received 19 May 2003

Accepted 15 July 2003

\section{REFERENCES}

1 Rosendaal FR. Venous thrombosis: a multicausal disease. Lancet 1999:353:1167-73.

2 Falconer DS. Introduction to quantitative genetics. London: Longman, 1989

3 Weiss KM. Segregation analysis: quantitative traits in families. In: Genetic variation and human disease. Principles and evolutionary approaches. Cambridge: Cambridge University press, 1993.

4 Williams JT, Van Eerddwegh P, Almasy L, et al. Joint multipoint linkage analysis of multivariate qualitative and quantitative traits. I. Likelihood formulation and simulation results. Am J Hum Genet 1999:65:1134-47.

5 Almasy L, Blangero J. Multipoint quantitative trait analysis in general pedigrees. Am J Hum Genet 1998;62:1198-211.

6 Souto JC, Almasy L, Borrell M, et al. Genetic susceptibility to thrombosis and its relationship to physiological risk factors: the GAIT study. Am J Hum Genet 2000:67:1452-9.

7 Soria JM, Almasy L, Souto JC, et al. A quantitative-trait locus in the human factor XII gene influences both plasma factor XII levels and susceptibility to thrombotic disease. Am J Hum Genet 2002;70:567-74.

8 Soria JM, Almasy L, Souto JC, et al. A new locus on chromosome 18 that influences normal variation in activated protein $C$ resistance phenotype and factor VIII activity and its relation to thrombosis susceptibility. Blood 2003; 101:163-7.

9 Soria JM, Almasy L, Souto JC, et al. Linkage analysis demonstrates that the prothrombin G20210A mutation jointly influences plasma prothrombin levels and risk of thrombosis. Blood 2000;95:2780-5.

10 Hillarp A, Hessing M, Dahlbäck B. Protein S binding in relation to the subunit composition of human C4b-binding protein. FEBS Lett 1989;159:53-6.

11 Dahlbäck B. Purification of human C4b-binding protein and formation of its complex with vitamin K-dependent protein S. J Biochem 1983;209:847-56.

12 Dahlbäck B. Inhibition of protein Ca cofactor function of human and bovine protein S by C4b-binding protein. J Biol Chem 1986;261:12022-7.

13 Taylor FB Jr, Dahlbäck B, Chang ACK, et al. Role of free protein S and C4b binding protein in regulating the coagulant response to Escherichia coli. Blood 1995;86:2642-52.

14 Comp PC, Nixon RR, Cooper MR, et al. Familial protein S deficiency is associated with recurrent thrombosis. J Clin Invest 1984;74:2082-8.

15 Esparza-Gordillo J, Soria JM, Buil A, et al. Genetic determinants of variation in the plasma levels of the C4b-binding protein (C4BP) in Spanish families. Immunogenetics 2003;54:862-6.

16 Souto JC, Almasy L, Borrell M, et al. Genetic determinants of hemostasis phenotypes in Spanish families. Circulation 2000;101:1546-51.

17 Almasy L, Soria JM, Souto JC, et al. A quantitative trait locus influencing free plasma protein $S$ levels on human chromosome 1q: results from the GAIT project. Arterioscler Thromb Vasc Biol 2003;23:508-11.
18 Sánchez-Corral P, Criado García O, Rodríguez de Córdoba S. Isoforms of human C4b-binding protein. I. Molecular basis for the C4BP isoform pattern and its variation in human plasma. J Immunol 1995; 155:4030-6.

19 Duggirgala R, Williams JT, Williams-Blangero S, et al. A variance component approach to dicotomous trait linkage analysis using a threshold model. Genet Epidemiol 1997; 14:987-92.

20 Kendall MG, Stuart A. Advanced theory of statistics. New York: Hafner, 1972.

21 Self SG, Liang K-Y. Asymptotic properties of maximum likelihood estimators and likelihood ratio tests under nonstandard conditions. J Am Stat Assoc 1987;82:605-10.

22 Hopper JL, Mathews JD. Extensions to multivariate normal models for pedigree analysis. Ann Hum Genet 1982;46:373-83.

23 Boehnke $M$, Lange K. Ascertainment and goodness of fit of variance component models for pedigree data. Prog Clin Biol Res 1984;147:173-92.

24 Souto JC, Almasy L, Borrell M, et al. Thromboplastin-thrombomodulinmediated time and serum folate levels are genetically correlated with the risk of thromboembolic disease: results from the GAIT project. Thromb Haemost 2002;87:68-73.

25 Koster T, Blan AD, Briet $E$, et al. Role of clotting factor VIII in effect of von Willebrand factor on occurrence of deep-vein thrombosis. Lancet 1995;345: 152-5.

26 den Heijer $\mathrm{M}$, Koster T, Blom HJ, et al. Hyperhomocysteinemia as a risk factor for deep-vein thrombosis. N Engl J Med 1996;334:759-62.

27 De Visser MCH, Rosendaal FR, Bertina RM. A reduced sensitivity for activated protein $C$ in the absence of factor $V$ Leyden increases the risk of venous thrombosis. Blood 1999;93:1271-6.

28 Comuzzie AG, Blangero J, Mahaney MC, et al. Genetic and environmental correlations among hormone levels and measures of body fat accumulation and topography. J Clin Endocrinol Metab 1996;81:597-600.

29 Brooks R. Negative genetic correlation between male sexual attractiveness and survival. Nature 2000;406:67-70.

30 Mahaney MC, Czerwinsky SA, Adachi T, et al. Plasma levels of extracellular superoxide dismutase in an Australian population: genetic contribution to normal variation and correlations with plasma nitric oxide and apolipoprotein A-I levels. Arterioscler Thromb Vasc Biol 2000;20:683-8.

31 Borgel D, Reny JL, Fischelis D, et al. Cleaved protein S (PS), total PS, free PS, and activated protein $\mathrm{C}$ cofactor activity as risk factors for venous thromboembolism. Clin Chem 2003;49:575-80.

32 Koster T, Rosendaal FR, Briët E, et al. Protein C deficiency in a controlled series of unselected outpatients: an infrequent but clear risk factor for venous thrombosis (Leyden Thrombophilia Study). Blood 1995;85:2756-61.

33 Liberti G, Bertina RM, Rosendaal FR. Hormonal state rather than age influences cut-off values of protein $\mathrm{S}$ : re-evaluation of the thrombotic risk associated with protein S deficiency. Thromb Haemost 1999:82:1093-6.

34 Faioni EM, Valsecchi C, Palla A, et al. Free protein S deficiency is a risk factor for venous thrombosis. Thromb Haemost 1997;78:1343-6.

35 Zöller B, García de Frutos P, Dahlbäck B. Evaluation of the relationship between protein $\mathrm{S}$ and $\mathrm{C} 4 \mathrm{~b}$-binding protein isoforms in hereditary protein $\mathrm{S}$ deficiency demonstrating type I and type III deficiencies to be phenotypic variants of the same genetic disease. Blood 1995:85:3524-31.

36 Griffin JH, Gruber A, Fernandez JA. Re-evaluation of total, free and bound protein $\mathrm{S}$ and $\mathrm{C} 4 \mathrm{~b}$-binding protein levels in plasma anticoagulated with citrate or hirudin. Blood 1992;79:3203-11. 